\title{
Effects of Hydrothermal Cooling and Magma Injection on Mid-Ocean Ridge Temperature Structure, Deformation, and Axial Morphology
}

\author{
Mark D. Behn ${ }^{1}$, Jian Lin ${ }^{2}$, and Maria T. Zuber ${ }^{3}$
}

Fault development at mid-ocean ridge spreading centers is strongly dependent on the thermal state of the axial lithosphere. Thermal conditions at a ridge axis are a combined function of spreading rate, mantle temperature, magma injection, and hydrothermal circulation. In this study, we test the sensitivity of fault development in slow-spreading environments to the efficiency of hydrothermal cooling and the depth extent of magma injection near the ridge axis. A 3-D finite difference scheme is first used to calculate axial temperature structure, and deformation is then modeled in 2-D vertical sections of lithosphere using a visco-plastic finite element model. Strain-rate softening in the brittle regime is used to simulate the rate-dependence of frictional strength observed in laboratory studies. This formulation results in the formation of localized zones of high strain rate (analogous to faults) that develop in response to the rheology and boundary conditions and are not imposed a priori. Comparing our numerical experiments with observed faulting at the center and ends of several segments along the slow-spreading Mid-Atlantic Ridge, we find that temperatures near the segment end must be warmer than predicted by previous models. These predicted high temperatures can be explained by either inefficient hydrothermal cooling in the shallow crust or heating of the upper mantle through magmatic accretion below the Moho. Because geophysical and geochemical evidence support efficient hydrothermal cooling in young oceanic lithosphere, we favor a model in which heat is supplied to the upper mantle beneath the ends of slow-spreading segments by either crystallization of rising asthenospheric melts or episodic lateral dike propagation from the segment center.

${ }^{1}$ Department of Terrestrial Magnetism, Carnegie Institution of Washington, Washington, DC.

${ }^{2}$ Department of Geology and Geophysics, Woods Hole Oceanographic Institution, Woods Hole, MA.

${ }^{3}$ Department of Earth, Atmospheric, and Planetary Sciences, Massachusetts Institute of Technology, Cambrige, MA, also at Laboratory for Terrestrial Physics, NASA Goddard Space Flight Center, Greenbelt, Maryland.

The Thermal Structure of the Ocean Crust and the Dynamics of Hydrothermal Circulation

Geophysical Monograph 148

Copyright 2004 by the American Geophysical Union

10.1029/148GM06

\section{INTRODUCTION}

The thermal state of young oceanic lithosphere is a complex function of spreading-rate, mantle temperature, magma injection, and hydrothermal cooling. Because of the difficulties in directly measuring subsurface thermal structure, researchers frequently rely on observables such as axial topography and abyssal hill fabric to infer thermal conditions near oceanic spreading centers. Fault evolution is highly sensitive to rheological heterogeneities within the brittle lithosphere and the underlying ductile asthenosphere [Davy et al., 1995; Heimpel and Olsen, 1996; Cowie, 1998]. Thus, by incorporating experimentally determined rheological laws 
in thermo-mechanical models of lithospheric stretching, the observed fault patterns can be used to place important constraints on axial thermal structure [e.g., Sleep and Rosendahl, 1979; Phipps Morgan et al., 1987; Lin and Parmentier, 1989; Chen and Morgan, 1990a; Shaw and Lin, 1996; Poliakov and Buck, 1998].

Using this approach Malinverno and Cowie [1993] and Shaw and Lin [1996] attributed the first-order dependence of fault style on spreading rate to changes in the mechanical strength of the lithosphere caused by the difference in thermal regime between fast- and slow-spreading ridges. Systematic variations in rift morphology are also observed along individual segments of the slow-spreading Mid-Atlantic Ridge (MAR). For example, MAR segments are often characterized by hour-glass shaped rift valleys that become wider and deeper toward the segment ends [e.g., Sempéré et al., 1993]. Coinciding with this change in rift morphology is an observed increase in the size and spacing of normal faults and abyssal hills from the segment center to the segment ends [e.g., Shaw, 1992; Shaw and Lin, 1993]. These changes in axial topography and fault style have been attributed to segment-scale variations in axial thermal structure [Shaw and Lin, 1993; 1996].

Along-axis thermal gradients can develop due to 3-D mantle upwelling [Phipps Morgan and Forsyth, 1988], the juxtaposition of old and therefore cold lithosphere across transform and non-transform offsets [Macdonald and Luyendyk, 1977; Forsyth and Wilson, 1984], and enhanced magmatic accretion near segment centers [Kuo and Forsyth, 1988; Lin et al., 1990; Lin and Phipps Morgan, 1992; Tolstoy et al., 1993; Detrick et al., 1995; Hooft et al., 2000]. However, several lines of evidence suggest that the along-axis thermal gradients at many slow-spreading segments may be smaller than previously proposed. Escartín et al. [1999] used a combination of deep-towed side-scan sonar and high resolution bathymetry data to show that fault spacing at the $29^{\circ} \mathrm{N}$ segment of the MAR does not necessarily increase systematically toward the segment end. Instead, fault spacing remains relatively constant from the segment center to the outside-corner crust near the ridge-transform intersection, increasing only on the insidecorner crust. The asymmetry across the segment end suggests faulting in this region may be affected more by mechanical interactions with the active segment offset than by an alongaxis temperature gradient. The lack of a significant increase in the maximum depth of seismicity along the $29^{\circ} \mathrm{N}$ segment is also indicative of a small along-axis thermal gradient [Wolfe et al., 1995].

Chen and Lin [1999] showed that much of the hour-glass shape of the rift valley south of the Atlantis transform (MAR $28^{\circ}-30^{\circ} \mathrm{N}$ ) is a result of isostatic compensation of along-axis crustal thickness variations. When this crustal signal is removed the residual (or tectonic) rift-valley width remains relatively constant along-axis. A similar difference between the topographically-defined and the tectonically-defined rift-valley is observed at ends of the $\mathrm{OH}-1$ segment of the MAR (see Figure 1). The OH-1 segment is the northernmost of three major segments bounded by the Oceanographer and Hayes Fracture Zones, and is characterized by a prominent hourglass shaped morphology [Gràcia et al., 1999; Rabain et al., 2001]. Defining the rift valley based on the peak topography on either side of the ridge axis, the rift half-width is observed to be $10-20 \mathrm{~km}$ near the ends of the $\mathrm{OH}-1$ segment. In contrast, if rift width is measured as the distance between the first large fault scarps $(>300-500 \mathrm{~m})$ on either side of the ridge axis, the segment ends are characterized by rift halfwidths of only $5-7 \mathrm{~km}$. The location of these large fault scarps indicates that significant brittle strain has accumulated near the ridge axis and implies a relatively thin brittle lithosphere even at the ends of the OH-1 segment. The narrowness of the tectonic rift valley is particularly surprising at the northern end of the segment, where the large age discontinuity across the Oceanographer Transform should result in significant conductive cooling and thicker lithosphere at the segment end.

Similar differences in the topographic and tectonic rift-valley width are observed at many other segments along the MAR. Figure 2 illustrates tectonic rift half-width (defined by half of the distance between the inner-most pair of large fault scarps) as a function of crustal thickness for a number of MAR segments where crustal thickness has been measured seismically. In all but one of the segments examined, the tectonic half-width near the segment end is less than $8 \mathrm{~km}$ and tends to be 4-8 km narrower than the topographically-defined rift-valley. We hypothesize that the tectonic rift valley is a direct reflection of the zone of active faulting at a ridge axis, while the topographic rift valley is the combined expression of several factors, including isostatic uplift associated with along-axis variations in crustal thickness [e.g., Chen and Lin, 1999] and flexural uplift associated with faulting. In many locations several large fault scarps are located between the rift axis and the location of maximum topography (e.g., Figure 1b). In these situations the overall morphology of the rift valley likely reflects flexural uplift associated with multiple generations of fault formation.

In this study, we examine the implications of tectonic rift width for axial thermal structure in slow spreading environments. Specifically, we test the sensitivity of fault development to the efficiency of hydrothermal cooling and the depth extent of magma injection near a ridge axis using a visco-plastic finite element model. Our modeling approach incorporates the rate-dependence of frictional strength observed in laboratory studies and results in the formation of localized zones of high strain rate (analagous to faults), which develop in 
(a)

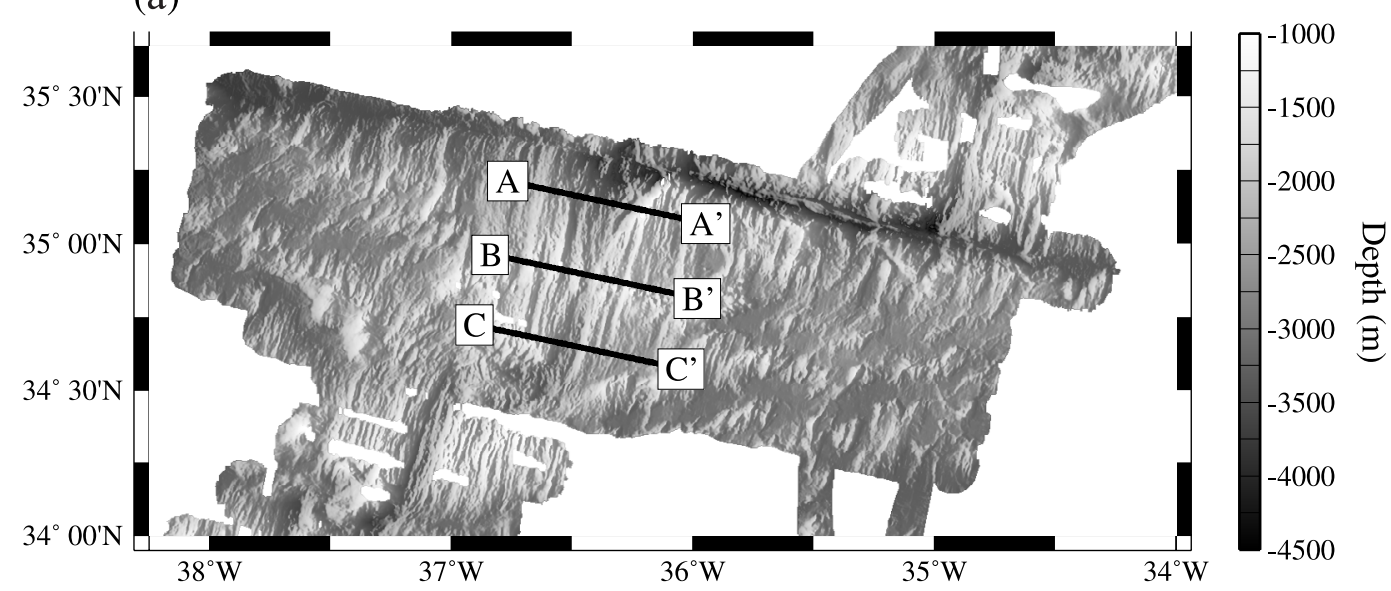

(b)

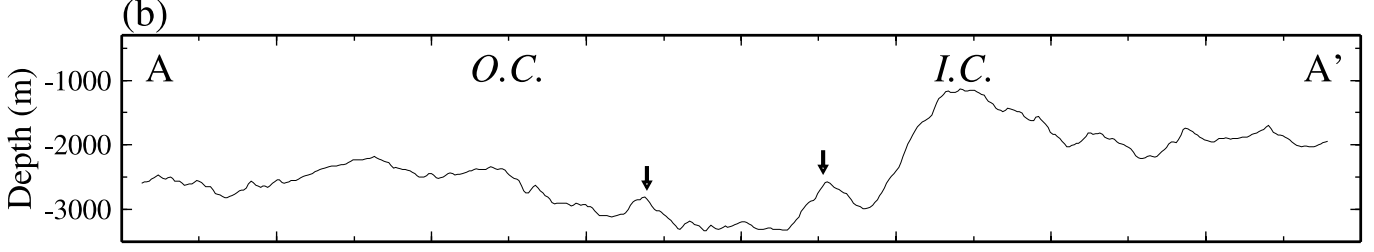

(c)

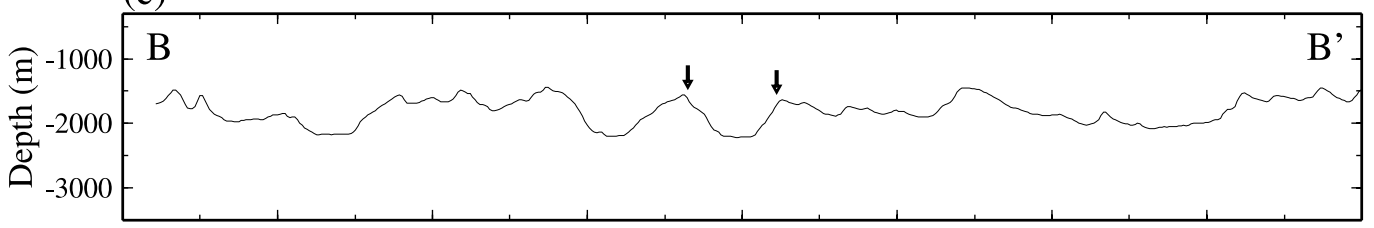

(d)

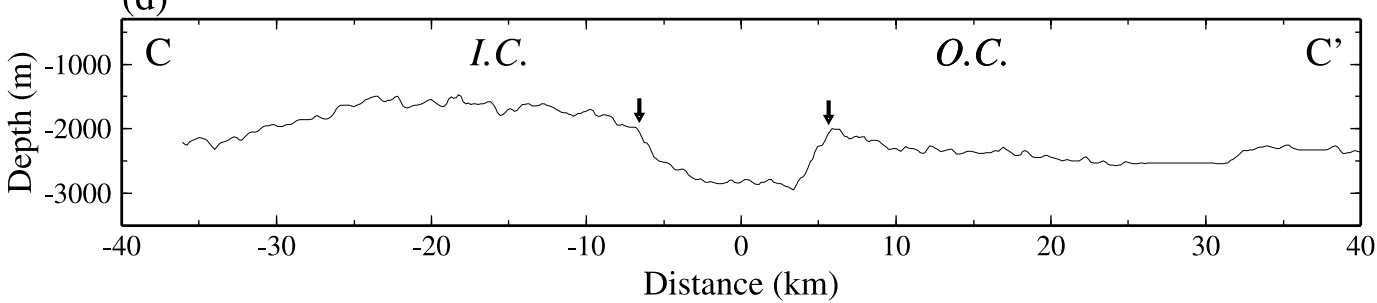

Figure 1. (a) SIMRAD bathymetry map of the $\mathrm{OH}-1$ and $\mathrm{OH}-2$ segments south of the Oceanographer Fracture Zone (100-m grid spacing) at the MAR [Rabain et al., 2001]. Illumination is from N285'. Solid lines illustrate profiles shown in (b) A-A', (c) B-B' and (d) C-C'. Small arrows denote the locations of the innermost major fault scarps (>500 m). The observed rift half-width increases from 3-4 km at the segment center to 4-7 km at the segment ends.

response to the rheology and boundary conditions. This formulation is advantageous because it allows us to investigate the style of faulting near a ridge axis over a wide range of thermal conditions without imposing the location of the faults a priori. Comparing the results of our numerical experiments to the tectonic rift width at the center and ends of segments along the MAR, we find that crustal and upper mantle temperatures near segment ends must be warmer than predicted by previous models [e.g., Shaw and Lin, 1996]. To generate these high temperatures, we show that either hydrothermal cooling must be very inefficient in the shallow crust or heat must be emplaced in the upper mantle due to magmatic accretion below the Moho.

\section{MODEL DESCRIPTION}

We use a two-step approach to model the zone of active faulting as a function of axial thermal structure in slow-spreading environments. A 3-D temperature model is first calculated incorporating the mantle flow field, magma injection, and 


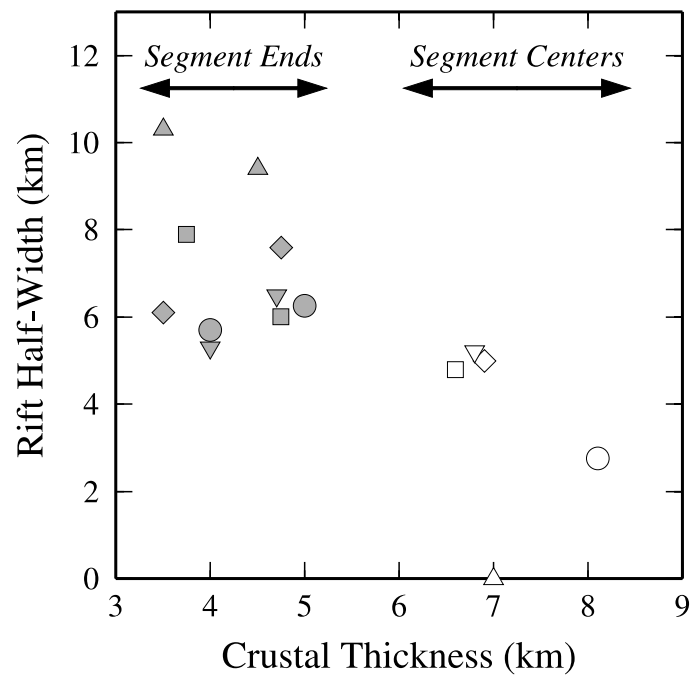

Figure 2. Rift half-width versus crustal thickness at the OH-1 (circles), $\mathrm{OH}-2$ (diamonds), OH-3 (squares), $29^{\circ} \mathrm{N}$ (inverted triangles), and $33^{\circ} \mathrm{S}$ (triangles) segments of the Mid-Atlantic Ridge. Segment centers are denoted with open symbols and segment ends with filled symbols. Rift half-width was determined from the distance between the first major fault scarp ( $>300-500 \mathrm{~m})$ on either side of the spreading axis. Crustal thickness estimates are taken from a combination of seismic refraction and gravity data: OH-1, OH-2, and OH-3 [Hooft et al., 2000], 29 $\mathrm{N}$ [Lin et al., 1990; Wolfe et al., 1995], and $33^{\circ} \mathrm{S}$ [Kuo and Forsyth, 1988; Tolstoy et al., 1993]. Note that rift-half width generally decreases with increasing crustal thickness.

hydrothermal cooling. The resulting temperature field is then used to calculate the location of fault formation in 2-D vertical sections of lithosphere across the center and end of a typical ridge segment.

\subsection{3-D Thermal Structure}

The 3-D temperature structure is calculated using the technique of Shaw and Lin [1996], which incorporates conductive and advective heat transport in mantle flow driven by the separation of surface plates. The predicted mantle flow field is strongly sensitive to the plate boundary geometry. For example, longer offsets between spreading segments tend to generate a more 3-D pattern of mantle upwelling, resulting in enhanced cooling near the segment ends [Phipps Morgan and Forsyth, 1988]. The plate geometry used in this study consists of a $100-\mathrm{km}$ spreading segment bounded by a $150-\mathrm{km}$ offset to the north and a $35-\mathrm{km}$ offset to the south, simulating the effects of a transform and non-transform offset, respectively (Figure 3a). This spreading geometry is similar to that observed at the OH-1 segment of the MAR and is ideal for examining end-member models of along-axis thermal variability at slowspreading ridge segments.
Hydrothermal cooling is modeled by enhancing the thermal conductivity by a factor $N u$ above a threshold depth of 6 $\mathrm{km}$ and in regions where the temperature is below $700^{\circ} \mathrm{C}$. This parameterization implies that in situations where shallow crustal temperatures are high, hydrothermal cooling will only extend down to the $700^{\circ} \mathrm{C}$ isotherm. The threshold depth represents the maximum pressure at which cracks are predicted to remain open for hydrothermal circulation, while the cut-off temperature is consistent with the maximum alteration temperature observed in lower crustal rocks [Kelley and Gillis, 2002].

Magma injection is simulated by including a heat source at the ridge axis that includes both the injection temperature and the latent heat of the crystallizing magma. The injection zone has a width of $0.5 \mathrm{~km}$ and a height of $h_{a}$ (Figure $3 \mathrm{~b}$ ). Shaw and Lin [1996] considered only cases in which the height of the injection zone was equal to the crustal thickness, $t_{c}$. In this study, however, we relax that condition and allow $h_{a}$ to vary independently of $t_{c}$. The implications of this assumption will be discussed in detail later in the text.
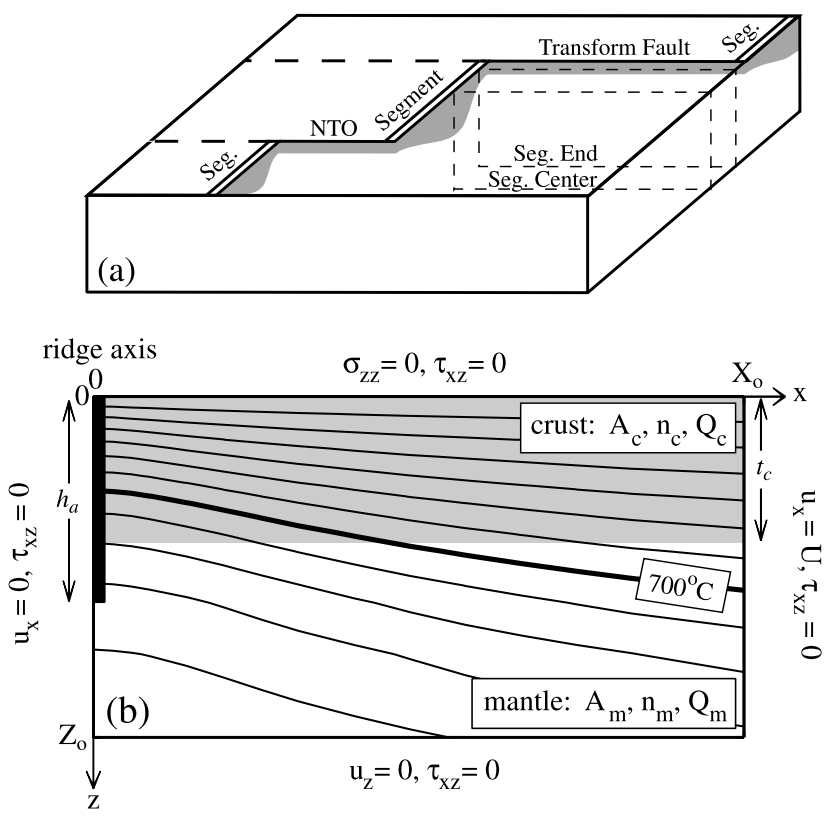

Figure 3. (a) 3-D model geometry used to calculate temperature structure along a ridge segment. Dashed lines illustrate the location of the 2-D vertical sections used to model fault formation at the center and end of the segment. (b) Model setup for mechanical models of lithospheric stretching. The model space is symmetric about the ridge axis, with dimensions $X_{\mathrm{o}}=45 \mathrm{~km}$ and $Z_{\mathrm{o}}=40 \mathrm{~km}$. A uniform horizontal velocity of $1 \mathrm{~cm} / \mathrm{yr}$ is applied to the right-hand side of the model space, and extension is continued until $1 \%$ total strain is achieved. Crustal thickness, $t_{c}$, is constant across-axis, with the crust and mantle rheological parameters given by $n_{c}, A_{c}, Q_{c}$ and $n_{m}, A_{m}, Q_{n}$, respectively (Table 1$)$. The magma injection zone (solid black region) has a width of $0.5 \mathrm{~km}$ and a height of $h_{a}$. 


\subsection{Mechanical Model of Fault Formation}

The calculated 3-D temperature models are used as the input thermal conditions to a Lagrangian visco-plastic strainrate-dependent finite element model. Strain-rate softening in the brittle layer is used to simulate the rate-dependence of frictional strength observed in laboratory studies [e.g., Dieterich, 1979; Ruina, 1983]. Both analytical [Montési and Zuber, 2002] and numerical [Neumann and Zuber, 1995; Behn et al., 2002; Montési and Zuber, 2003] studies have shown that strain-rate softening in the brittle regime can result in the formation of localized zones of high strain rate, analogous to faults. Because these zones develop in response to the rheology and boundary conditions, the calculated deformation field can be used to predict the preferred location of fault initiation over a range of thermal and rheologic conditions.

For viscous flow we assume a non-Newtonian temperaturedependent rheology [Kirby, 1983; Kohlstedt et al., 1995]

$$
\dot{\varepsilon}=A\left(\sigma_{1}-\sigma_{3}\right)^{n} \exp (-Q / R T)
$$

where $\dot{\varepsilon}$ is the uniaxial strain rate, $\sigma_{1}$ and $\sigma_{3}$ are the maximum and minimum principle stresses, $n$ is the power law exponent, $Q$ is the molar activation energy, $A$ is a material strength constant, $T$ is the temperature, and $R$ is the gas constant. Although the relationship between stress and strain rate is nonlinear, we can define a linearized viscosity law [e.g., Chen and Morgan, 1990b; Boutilier and Keen, 1994] by

$$
\tau_{i j}=\sqrt{2} \eta \dot{\varepsilon}_{i j}
$$

where $\tau_{\mathrm{ij}}$ is the stress tensor, $\eta$ is the effective viscosity, and $\dot{\varepsilon}_{i j}$ is the strain-rate tensor. This linearization leads to an expression for the apparent effective Newtonian viscosity

$$
\eta=B \dot{\varepsilon}_{\mathrm{II}}^{(1-n) / n} \exp (Q / n R T)
$$

where $\dot{\varepsilon}_{\text {I I }}$ is the second invariant of the stain rate tensor, and $B$ is a material constant related to $A$.

In the brittle regime, strength is assumed to be controlled by a frictional resistance law [e.g., Byerlee, 1978; Scholz, 1990]

$$
\tau_{\max }=\sigma_{\mathrm{o}}-\mu \sigma_{n}
$$

where $\sigma_{0}$ is the cohesive strength, $\mu$ is the coefficient of friction, and $\sigma_{n}$ is approximately equal to the lithostatic stress. The rate dependence of frictional strength is simulated by defining an apparent friction coefficient, $\mu^{\prime}$, as

$$
\mu^{\prime}=\mu_{0}\left[1-\gamma \log _{10}\left(\dot{\varepsilon}_{\mathrm{II}} / \dot{\varepsilon}_{0}\right)\right]
$$

where $\mu_{\mathrm{o}}$ is the reference coefficient of friction, $\gamma$ is the strainrate softening coefficient, and $\dot{\varepsilon}_{\mathrm{o}}$ is the reference strain-rate. This formulation not only simulates strain-rate weakening for $\dot{\varepsilon}_{\mathrm{II}}>\dot{\varepsilon}_{\mathrm{o}}$ but also generates strengthening in regions where $\dot{\varepsilon}_{\text {I I }}<\dot{\varepsilon}_{\mathrm{o}}$. Behn et al. [2002] showed that $\gamma \geq 0.10$ results in efficient strain localization in models of lithospheric deformation for plausible rheological structures, and we choose $\gamma=0.15$ for the numerical experiments presented in this study. Acknowledging that this approach neglects many of the complexities of the earthquake process, we interpret these regions of high strain-rate to be analogous to fault zones. Note that in the visco-plastic formulation implemented here, the pattern of deformation is found to be relatively insensitive to the values of $\mu_{\mathrm{o}}$ and $\sigma_{\mathrm{o}}$.

Following the procedures described in Neumann and Zuber [1995] and Behn et al. [2002] we calculate deformation in two 2-D vertical sections of lithosphere near the center and end of the segment. At each time-step the element viscosities are calculated from the temperature and evolving strain-rate fields. If the resulting maximum principle shear stress calculated from Equation 2 is greater than the frictional failure criterion, $\tau_{\max }$, the effective viscosity of the element is reset to $\eta=\tau_{\max } / \sqrt{2} \dot{\varepsilon}_{\mathrm{II}}$. The initial element viscosities are calculated assuming a uniform background strain-rate of $10^{-14} \mathrm{~s}^{-1}$.

We stress that the numerical experiments presented here should be treated only as a proxy for the initial pattern of faulting that develops for a given set of thermal conditions, rather than as a method to study the evolution of individual faults over geologic time. The rotation of fault blocks in highly extended terrains generates large flexural stress [e.g., Forsyth, 1992; Buck, 1993] that are not accounted for in our viscoplastic formulation. By limiting our calculations to $1 \%$ total strain, we can safely ignore these elastic stresses and also eliminate numerical inaccuracies associated with the distortion of model elements.

Crustal thicknesses of $8 \mathrm{~km}$ and $3 \mathrm{~km}$ are used for the center and end of the segment, respectively. These values are based on end-member segment-scale variations in crustal thickness observed in seismic refraction experiments at the MAR [e.g., Tolstoy et al., 1993; Hooft et al., 2000]. We assume the dry diabase flow law of Mackwell et al. [1998] for the crust $\left(n=4.7, A=1.9 \times 10^{2} \mathrm{MPa}^{-\mathrm{n}} \mathrm{s}^{-1}, Q=485 \mathrm{~kJ} \mathrm{~mol}^{-1}\right)$ and the dry dunite flow law of Chopra and Paterson [1984] for the mantle $\left(n=3, A=1.0 \times 10^{3} \mathrm{MPa}^{-\mathrm{n}} \mathrm{s}^{-1}, Q=520 \mathrm{~kJ} \mathrm{~mol}^{-1}\right)$. These dry rheologies are appropriate for young oceanic lithosphere that has been dewatered due to melting associated with crustal formation [Hirth et al., 1998].

Deformation is driven by applying a uniform horizontal velocity of $1 \mathrm{~cm} / \mathrm{yr}$ to the right-hand side of the model space $\left(x=X_{\mathrm{o}}\right)$. For numerical efficiency, a symmetry condition is imposed on the left-hand side of model $(x=0)$ by setting the 
horizontal velocity, $u_{x}$ and the shear stress, $\tau_{x z}$, equal to zero. The model dimensions ( $\left.X_{\mathrm{o}}=45 \mathrm{~km}, Z_{\mathrm{o}}=40 \mathrm{~km}\right)$ are specified to ensure that the boundaries do not influence the final solution and the finite element grid is adjusted to give maximum resolution (grid size of $300 \mathrm{~m} \times 300 \mathrm{~m}$ ) near the ridge axis. The boundary conditions and driving forces are illustrated in Figure $3 \mathrm{~b}$ and a list of all model parameters is given in Table 1 .

\section{NUMERICAL RESULTS}

Deformation is calculated over a wide range of thermal conditions, varying both the height of the magma injection zone, $h_{a}$, and the efficiency of hydrothermal cooling, $N u$. Plate 1 shows the predicted pattern of deformation at the segment center for $N u=4$ and $h_{a}=6 \mathrm{~km}$. Strain is calculated to be focused within two inward-dipping shear zones that intersect the surface at distances of $\sim 4 \mathrm{~km}$ and $\sim 12 \mathrm{~km}$ from the ridge axis, respectively, and an outward-dipping shear zone connecting the two inward-dipping zones at depth of 5-10 $\mathrm{km}$. In general, stress increases with depth to a maximum value of $\sim 140 \mathrm{MPa}$ at the brittle-ductile transition and then decreases abruptly in the underlying ductile asthenosphere (Plate 1, top-left panel). Corresponding effective viscosities are shown in Plate 1 (lower-left panel), with elements undergoing brittle failure shaded in grey. Within the shear zones stresses are low due to the efficient strain-rate weakening in these regions. Also, note that the brittle-ductile transition has been deformed beneath the axis, illustrating the coupling between the evolving stress and strain fields.

The flow-field shown in Plate 1 (top-right panel) is very similar to that observed in analogue experiments of extension in clay layers [e.g., Cloos, 1968], as well as earlier studies based on slip-line analysis [Lin and Parmentier, 1990]. These similarities include both the central graben development, and also the formation of weak antithetic shear zones near the surface intercept of the outer fault. The development of multiple active shear zones, both synthetic and antithetic, illustrates the importance of the interaction between stress and strain in determining the preferred style of deformation. Similar styles of faulting have been observed in modeling studies that incorporate cohesion loss on fault surfaces through a strain-weakening rheology in the brittle crust [Poliakov and Buck, 1998; Lavier et al., 2000; Lavier and Buck, 2002]. Both approaches incorporate the coupling between stress and strain through non-linear frictional resistance laws, and represent an important advance over models that infer fault development using an elastic plate formulation [e.g., Forsyth, 1992; Shaw and Lin, 1996; Escartin et al., 1997]. In these elastic formulations fault location and dip must be specified, rather than developing in response to the evolving stress field. Thus, this

Table 1. Model Parameters

\begin{tabular}{|c|c|c|c|}
\hline & Definition & Value & Units \\
\hline$u$ & spreading half-rate & 1.0 & $\mathrm{~cm} \mathrm{yr}^{-1}$ \\
\hline$T_{m}$ & mantle temperature & 1350 & ${ }^{\circ} \mathrm{C}$ \\
\hline$N u$ & efficiency of hydrothermal cooling & $1-12$ & \\
\hline$T_{\text {cut }}$ & maximum temperature of hydrothermal cooling & 700 & ${ }^{\circ} \mathrm{C}$ \\
\hline$z_{\text {cut }}$ & maximum depth of hydrothermal cooling & 6 & $\mathrm{~km}$ \\
\hline$h_{a}$ & magma injection zone height & $2-10$ & $\mathrm{~km}$ \\
\hline$T_{i}$ & magma injection temperature & 1150 & ${ }^{\circ} \mathrm{C}$ \\
\hline$l_{h}$ & latent heat of magma & $7.5 \times 10^{5}$ & $\mathrm{~J} \mathrm{~kg}^{-1}$ \\
\hline$c_{p}$ & specific heat of magma & 1250 & $\mathrm{~J} \mathrm{~kg}^{-1}{ }^{\circ} \mathrm{C}^{-1}$ \\
\hline$t_{c}$ & crustal thickness (seg. center, seg. end) & 8,3 & $\mathrm{~km}$ \\
\hline$W$ & width of the emplacement zone & 0.5 & $\mathrm{~km}$ \\
\hline$\kappa$ & thermal diffusivity & $10^{-6}$ & $\mathrm{~m}^{2} \mathrm{~s}^{-1}$ \\
\hline$R$ & gas constant & 8.3144 & $\mathrm{~J} \mathrm{~mol}^{-1} \mathrm{~K}^{-1}$ \\
\hline$n_{c}, n_{m}$ & power law exponent (crust, mantle) & $4.7,3$ & \\
\hline$A_{c}, A_{m}$ & material strength constant (crust, mantle) & $1.9 \times 10^{2}, 1.0 \times 10^{3}$ & $\mathrm{MPa}^{-\mathrm{n}} \mathrm{s}^{-1}$ \\
\hline$Q_{c}, Q_{m}$ & molar activation energy (crust, mantle) & 485,520 & $\mathrm{~kJ} \mathrm{~mol}^{-1}$ \\
\hline$\rho_{c}, \rho_{m}$ & density (crust, mantle) & 2700,3300 & $\mathrm{~kg} \mathrm{~m}^{-3}$ \\
\hline$\eta_{\mathrm{eff}}$ & effective viscosity & & $\mathrm{Pas}$ \\
\hline$\tau_{\max }$ & maximum differential stress & & $\mathrm{MPa}$ \\
\hline$\mu^{\prime}$ & effective coefficient of friction & & \\
\hline$\mu_{\mathrm{o}}$ & reference coefficient of friction & 0.6 & \\
\hline$\gamma$ & strain rate softening coefficient & 0.15 & \\
\hline$\dot{\varepsilon}_{\mathrm{II}}$ & second invariant of the strain rate tensor & & $\mathrm{s}^{-1}$ \\
\hline$\dot{\varepsilon}_{\mathrm{o}}$ & reference strain rate & $10^{-14}$ & $\mathrm{~s}^{-1}$ \\
\hline$w_{r}$ & rift half-width & & $\mathrm{km}$ \\
\hline$x, z$ & horizontal and vertical coordinates & & $\mathrm{km}$ \\
\hline$X_{\mathrm{o}}, Z_{\mathrm{o}}$ & horizontal and vertical dimensions of model space & 45,40 & $\mathrm{~km}$ \\
\hline
\end{tabular}


BEHN ET AL. 157
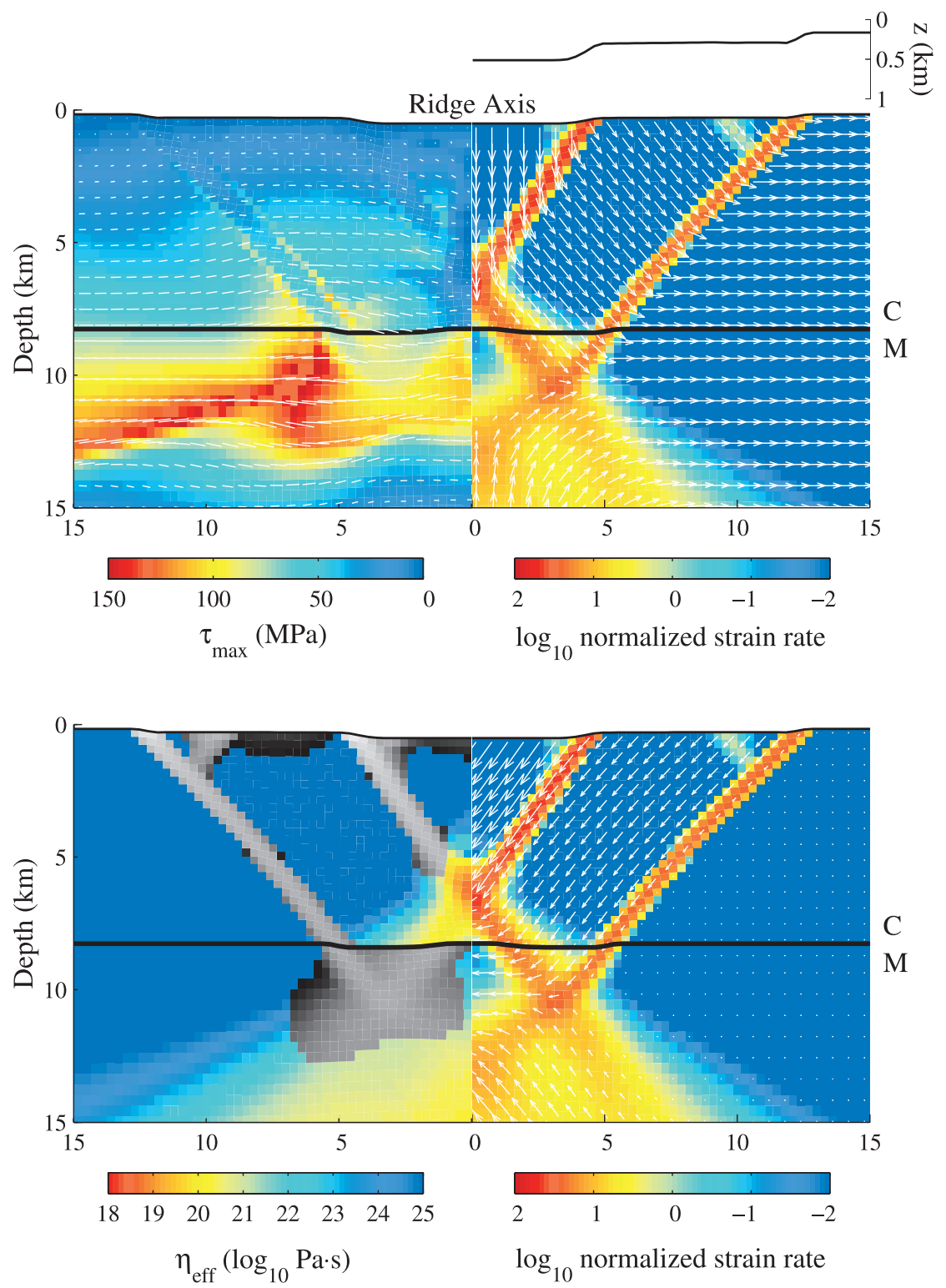

Plate 1. Numerical simulation illustrating the predicted pattern of deformation at the segment center for $N u=4$ and $h_{a}=$ $6 \mathrm{~km}$. (Top-right) Calculated strain-rates normalized to $\dot{\varepsilon}_{\mathrm{o}}$ after $1 \%$ total strain. White arrows show flow field relative to horizontal motion of the off-axis lithosphere. Black line illustrates boundary between the crust (C) and mantle (M). (Topleft) Maximum differential stress, $\tau_{\max }$. White lines indicate direction of maximum tensile stress with length scaled to the magnitude of $\tau_{\max }$ (Bottom-right) Normalized strain-rates with white arrows showing flow field relative to no motion of the off-axis lithosphere. (Bottom-left) Effective viscosity, $\eta_{\mathrm{eff}^{\circ}}$ Grey shading illustrates elements undergoing brittle failure. Strain is calculated to be focused in two inward-dipping shear zones that intersect the surface with rift-half widths of $\sim 4$ and $\sim 12 \mathrm{~km}$ from the ridge axis, respectively. 
approach is not suitable for accurately modeling the interaction and initiation of multiple sets of faults.

Plates 2 and 3 show the calculated strain-rate fields as a function of thermal structure for the center and northern end of the segment, respectively. We examine only the northern end of the segment because conductive cooling across the transform will generate a larger gradient in thermal conditions relative to the segment center than will the shorter non-transform offset to the south. By comparing the northern end of the segment with the segment center, we can investigate the effects of end-member thermal conditions on fault formation in slowspreading environments.

Deformation is calculated for $N u=1-12$ and $h_{a}=2-10$ $\mathrm{km}$. The wide range of thermal parameters was chosen to test the sensitivity of the predicted deformation field to a broad spectrum of possible temperature structures. In general, rift half-width, $w_{r}$, is calculated to increase with decreasing values of $h_{a}$ and increasing values of $N u$ (Figure 4). We define $w_{r}$ as the distance from the ridge axis $(x=0 \mathrm{~km})$ to the surface intercept of the inward-dipping shear zone. (Note that for thermal conditions in which two shear zones form, both an inner and outer rift half-width are predicted). We also find that for a given set of thermal parameters, $w_{r}$ is greater at the segment end than at the segment center. These first-order predictions are consistent with the results of Shaw and Lin [1996].

However, the numerical experiments conducted in this study also show interesting features not observed in previous studies. In particular, the formation of multiple inward-dipping faults is calculated to occur as a transitional regime between cold, wide single-fault rift zones and warm, narrow singlefault rift zones. For example, when $N u=8$, the calculated strain-rates at the segment center show wide rift zones $\left(w_{r} \approx\right.$ $15 \mathrm{~km}$ ) defined by a single fault for $h_{a}=2-6 \mathrm{~km}$, and a narrow single-fault rift $\left(w_{r} \approx 6 \mathrm{~km}\right)$ for $h_{a}=10 \mathrm{~km}$ (Plate 2). However, when $h_{a}=8 \mathrm{~km}$, the deformation field is characterized by two inward-dipping shear zones $\left(w_{r} \approx 6 \& 13 \mathrm{~km}\right)$. A similar style of transition from wide to narrow single-fault rifts is observed for $h_{a}=6 \mathrm{~km}$ and decreasing values of $N u$ (Plate 2). In reality, topographic stresses associated with continued slip on multiple faults may cause one fault to become preferred over the other. However, these results show the potential for slip in multiple fault zones near the ridge axis.

We also find that when high temperatures are present in the shallow crust beneath the ridge axis, a narrow $(\leq 1 \mathrm{~km})$ collapse feature is often predicted to form (red arrows in Plates 2 and 3). These collapse structures are typically bounded by nearly vertical shear zones. Similar features, often referred to as axial caldera troughs, are observed at many fast spreading ridges and are strongly correlated to the presence of a
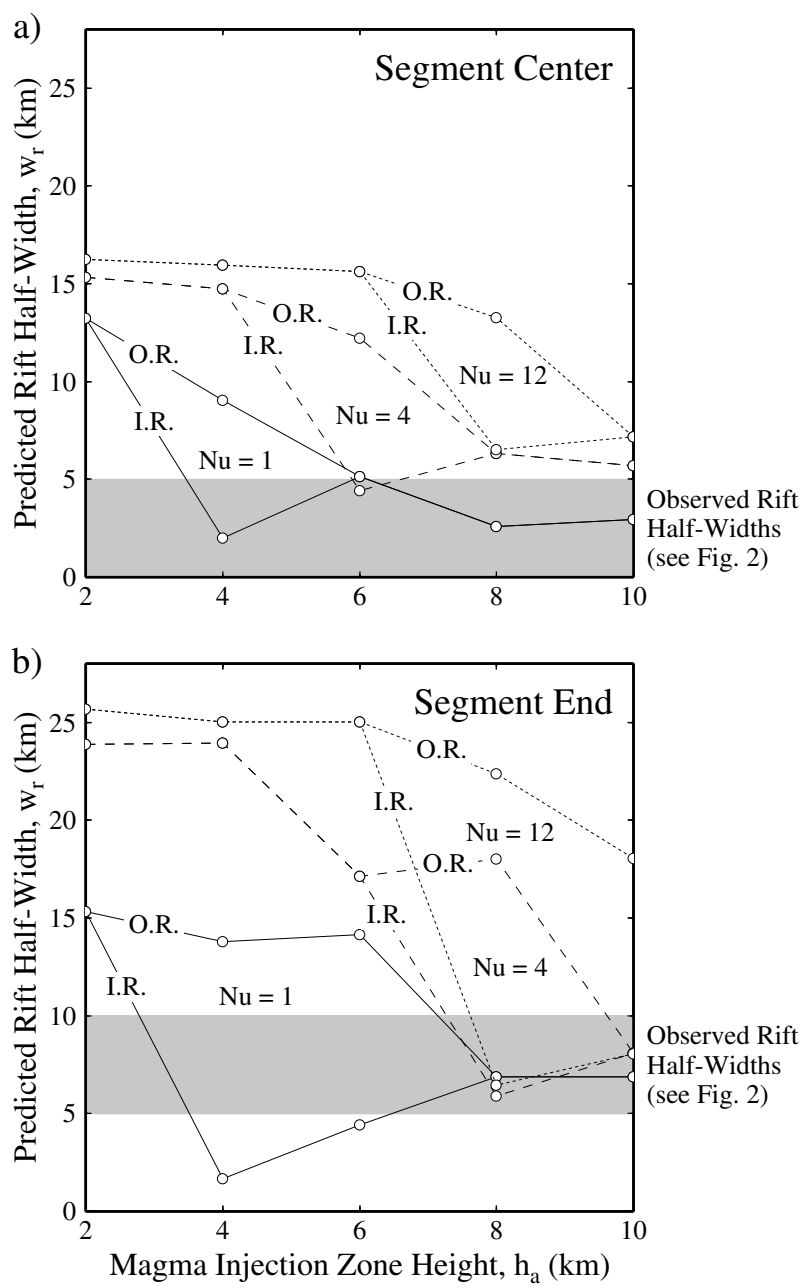

Figure 4. Summary of the predicted rift half-width, $w_{r}$, as a function of the magma injection zone height, $h_{a}$, at the (a) segment center and (b) segment end. Each symbol illustrates the results of one numerical experiment (see Plates 2 and 3). Calculated rift half-widths are shown for $N u=1$ (solid), $N u=4$ (dashed), and $N u=12$ (dotted). Note that in some cases two values of $w_{r}$ are predicted, corresponding to two sets of calculated faults. I.R. and O.R. refer to the inner and outer faults, respectively. In general, rift half-width is calculated to increase with decreasing values of $h_{a}$ and increasing values of $N u$.

shallow axial mamga chamber [e.g., Macdonald and Fox, 1988].

\section{COMPARISON OF PREDICTED AND OBSERVED RIFT WIDTHS}

The predicted deformation patterns were first compared to the axial bathymetry at $\mathrm{OH}-1$ segment to determine the thermal conditions that are most consistent with the observed tectonic rift width. The $\mathrm{OH}-1$ segment represents an ideal location 

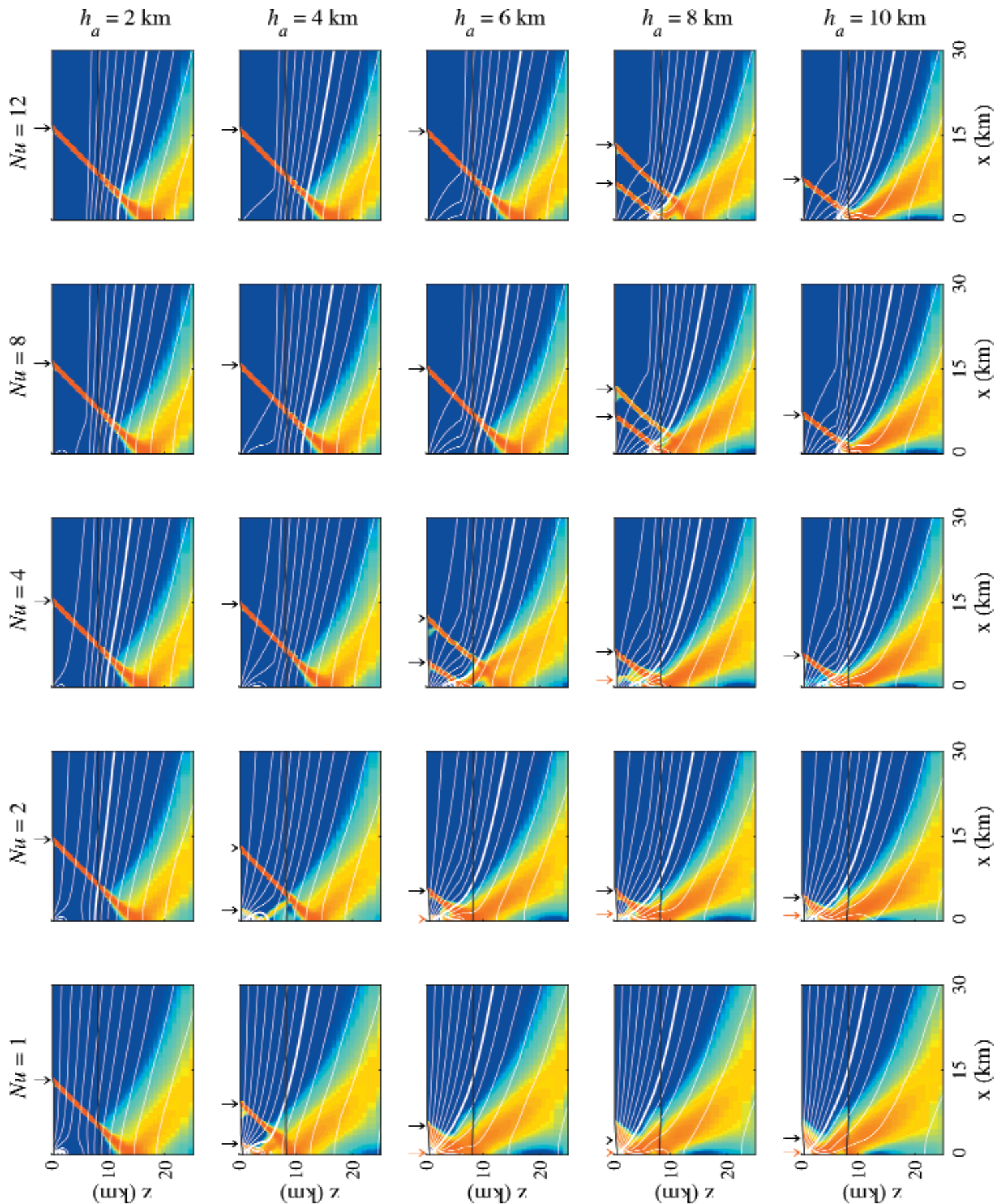

Plate 2. Numerical simulations illustrating the predicted pattern of deformation at the center of the segment for $N u=1-12$ and $h_{a}=2-10 \mathrm{~km}$. Each panel shows the results of one numerical experiment, with $N u$ increasing from left to right and $h_{a}$ increasing from top to bottom. Colors indicate calculated strain-rates normalized to $\dot{\varepsilon}_{\mathrm{o}}$ after $1 \%$ total strain (color scale shown in Plate 1). White lines show initial temperature field prior to deformation with contour interval of $100^{\circ} \mathrm{C}$. Black arrows indicate surface intercept of major inward-dipping fault zones, while red arrows denote vertical collapse features. A crustal thickness of $8 \mathrm{~km}$ is used for all numerical experiments at the segment center. Rheological parameters used for the crust and mantle are given in Table 1. 

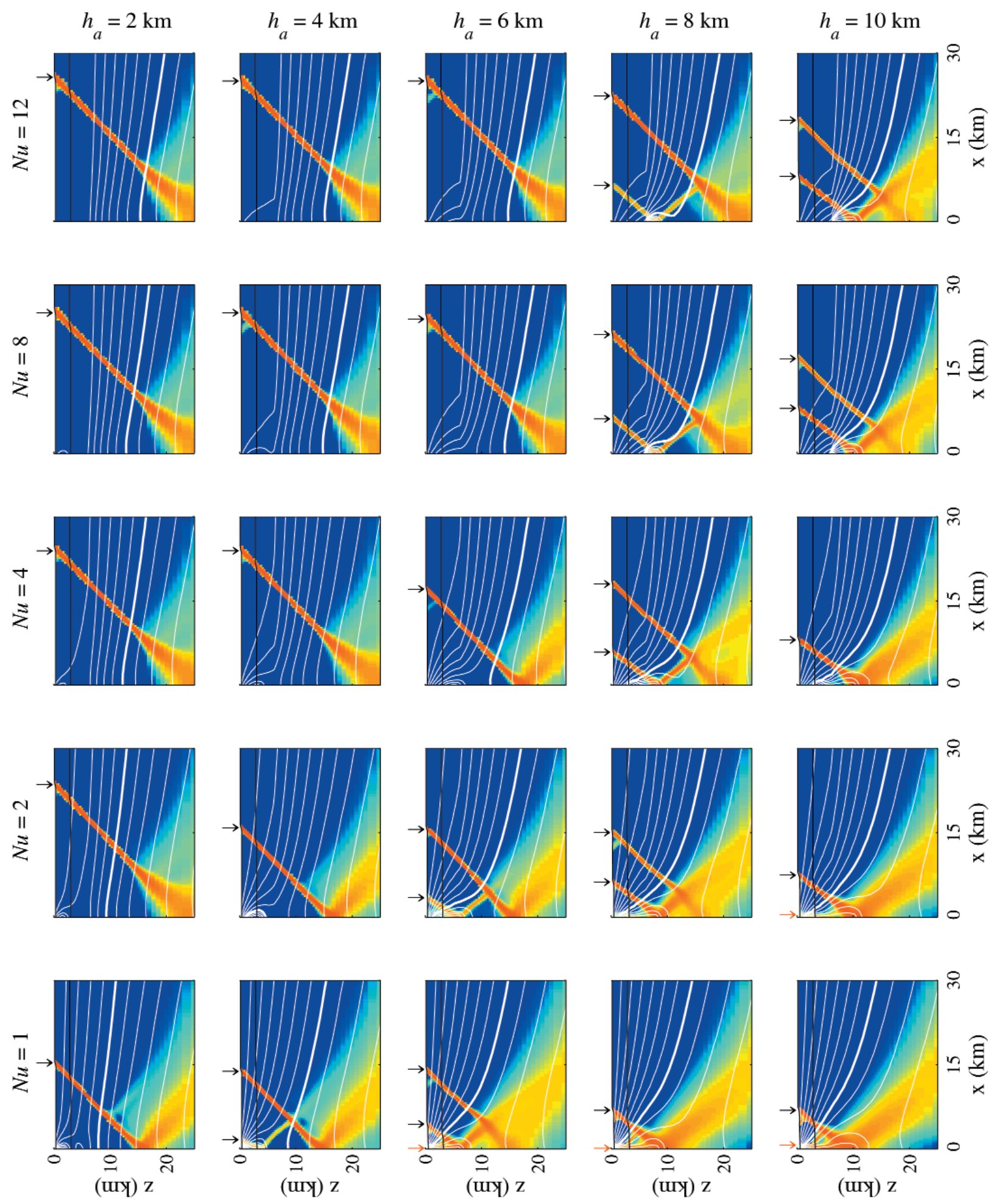

Plate 3. Numerical simulations illustrating the predicted pattern of deformation at the northern end of the segment for $N u=1-12$ and $h_{a}=2-10 \mathrm{~km}$. A crustal thickness of $3 \mathrm{~km}$ is used for all numerical experiments at the segment end. All other model parameters are the same as those used at the center of the segment (Plate 2). 
to constrain axial thermal structure, because the wealth of geophysical data that have been collected in the region. Specifically, the along-axis variability in tectonic rift width is well constrained by seafloor mapping of the axial valley floor and adjacent ridge flanks [Gràcia et al., 1999; Rabain et al., 2001]. In addition, seismic data constrain the along-axis variations in crustal thickness from a maximum of $8 \mathrm{~km}$ near the segment center to $4 \mathrm{~km}$ and $5 \mathrm{~km}$ at the northern and southern segment ends, respectively [Hooft et al., 2000; Hosford et al., 2001]. It is possible that multiple sets of faults are active at the OH-1 segment. A microearthquake study [Barclay et al., 2001] and hydroacoustic monitoring [Smith et al., 2002] show a tendency for seismicity to cluster at the inside corners of the $\mathrm{OH}-1$ segment. However, the limited number of events observed during these experiments are not sufficient to determine all faults that are currently active. Thus, because the offaxis extent of active deformation cannot be determined, we compare the rift half-width defined by the innermost calculated shear zone to the innermost observed fault scarp.

At the center of the $\mathrm{OH}-1$ segment, the tectonic rift halfwidth is observed to be $3-4 \mathrm{~km}$ (Figure 1c). Assuming the height of the magma injection zone is not less than the crustal thickness (i.e., $h_{a} \geq t_{c}$ the observed rift half-width is most consistent with $N u=1-2$ (Plate $2, h_{a}=8-10 \mathrm{~km}$ ). These thermal structures predict active faulting to depths of $\sim 5 \mathrm{~km}$, consistent with the observed depth of microseismicity at the segment center [Barclay et al., 2001]. In this case, the calculated location of the innermost shear zone is not highly sensitive to the efficiency of hydrothermal cooling for $h_{a} \geq 8 \mathrm{~km}$ (Figure 4). Thus, it is difficult to rule out cases with $N u \geq 4$.

Near the northern end of the $\mathrm{OH}-1$ segment, prominent inside-corner high topography is located 7-14 km from the ridge axis (Figure 1b). However the observed half-width of the inner rift valley appears to be only 4-7 km (Figures $1 \mathrm{~b}$ and 1d). Such a narrow rift half-width is consistent with $h_{a} \geq 4 \mathrm{~km}$ for $N u=1 ; h_{a} \geq 6 \mathrm{~km}$ for $N u=2$; and $h_{a} \geq 8 \mathrm{~km}$ for $N u \geq 4$ (Plate 3). This implies that with the exception of the numerical experiments with no hydrothermal cooling $(N u=1)$, the observed rift half-width requires a magma injection zone that extends $2-6 \mathrm{~km}$ below the base of the seismically-determined crust at northern end of the $\mathrm{OH}-1$ segment. It is interesting that in many of these cases deformation is predicted to localize in two shear zones, with the outer fault defining a rift half-width $\geq 14 \mathrm{~km}$.

We also compared the results of our numerical experiments to the observed tectonic rift width at several other MAR segments where crustal thickness has been determined seismically (Figure 2). Rift half-width at the center of these segments ranges from 0 to $5 \mathrm{~km}$, while the seismically-determined crustal thickness varies from 6 to $8 \mathrm{~km}$. We find that the predicted inner rift half-width is consistent with the observed half-widths for $h_{a} \approx t_{c}$ and a range of Nusselt numbers from 1-8 (Plate 2 and Figure 4a). Near the segment ends, observed rift half-width varies from 5 to $10 \mathrm{~km}$ with crustal thicknesses of $3-5 \mathrm{~km}$. These narrow rift half-widths are predicted only by models with either $h_{a} \approx t_{c}$ and $N u=1$, or $h_{a}>t_{c}$ and $N u>1$ (Plate 3 and Figure $4 b$ ). Thus, except in cases with no enhanced hydrothermal cooling, the magma injection zone must extend below the seismically-determined Moho near the segment ends to match the observed topography. In future studies, it will be interesting to test models that include either an isolated magma injection zone in the upper mantle or in multiple discrete zones throughout the crust and mantle to determine if these accretion zone geometries also generate faulting consistent with the observed tectonic rift widths at the ends of slow-spreading segments.

\section{DISCUSSION}

Previous studies of axial thermal structure [e.g., Phipps Morgan and Chen, 1993; Shaw and Lin, 1996] typically assume efficient hydrothermal cooling in the shallow lithosphere $(N u=8)$ and a magmatic accretion zone isolated to the crust $\left(h_{a} \leq t_{c}\right)$. In this formulation, heat supply at the center of a slow-spreading segment is greater than near the segment ends due to the along-axis gradient in crustal thickness. However, using these thermal parameters we predict rift widths that are significantly wider than observed at the ends of many MAR segments. For example, deformation at the northern end of the $\mathrm{OH}-1$ segment is calculated to localize in a single fault zone with $w_{r} \approx 20 \mathrm{~km}$. Such a wide rift is not consistent with the observed faulting (Figure 1) and indicates that the thermal parameters used in these earlier studies may significantly underestimate temperatures near the end of the $\mathrm{OH}-1$ segment. We propose two alternative explanations for this discrepancy and discuss their implications for magmatic and hydrothermal processes at slow-spreading ridges.

One explanation for the elevated temperatures at the ends of many MAR segments is that hydrothermal circulation does not significantly enhance thermal conductivity in the shallow crust. Assuming $N u=1$ and $h_{a}=8 \mathrm{~km}$, the predicted deformation at the segment center matches the observed rift half-widths shown in Figure 2. A narrow inner rift half-width consistent with the data can also be generated at the segment end with $N u=1$ and $h_{a}=4 \mathrm{~km}$ (Plate 3). A mechanism that could potentially limit the efficiency of hydrothermal cooling is the precipitation of hydrothermal minerals blocking fluid pathways [e.g., Sleep, 1991]. The sealing time of a porous medium is inversely proportional to the mass flux squared [Lowell and Yao, 2002]. This results in a negative feedback, in which the regions of most rapid fluid flow, and thus most effi- 
cient hydrothermal cooling, are also the regions that experience the most rapid decrease in permeability.

However, rapid sealing of fluid pathways is not consistent with geophysical and geochemical evidence for efficient hydrothermal cooling in young oceanic lithosphere. Crustal and upper-mantle seismic structure at $9^{\circ} 30^{\prime} \mathrm{N}$ on the East Pacific Rise indicate rapid cooling in the shallow crust near the ridge axis [Dunn et al., 2000]. This is supported by the systematic overprediction of heat flow in young oceanic crust by plate cooling models [Stein and Stein, 1992]. In addition, thermal modeling by Phipps Morgan and Chen [1993] showed that values of $N u \geq 8$ are required to accurately predict the depth and presence of an axial magma chamber over a wide range of spreading rates. Finally, altered primary mineral phases, vein assemblages, fluid inclusions, and oxygen isotopic measurements all indicate that hydrothermal flow occurs in the lower crust at temperatures up to $700^{\circ} \mathrm{C}$ [Kelley and Gillis, 2002]. Therefore, we favor an alternative model in which heat is supplied to the upper mantle at the ends of the slow-spreading segments by magmatic accretion beneath the Moho.

Cannat [1996] proposed that when the axial lithosphere is thicker than the seismically-determined crust, melt extracted from the asthenosphere may crystallize in the upper lithospheric mantle (Model 1 in Figure 5). Because crystallization only requires that temperatures in the surrounding rock be below the melt solidus $\left(1000^{\circ}-1200^{\circ} \mathrm{C}\right.$ [Sinton and Detrick, 1992]), significant latent heat may be released if rising asthenospheric melts begin crystallization below the Moho. This model is supported by petrogenetic studies of gabbros from slow-spreading ridges that showed fractional crystallization begins at pressures exceeding the ambient pressure at the base of the crust [Flower, 1981; Elthon et al., 1992; Ross and Elthon, 1997]. Furthermore, melt/rock reactions in rocks from ODP Site 920 show evidence for gabbroic melts crystallizing in peridotites at temperatures only slightly below the melt solidus [Cannat et al., 1997].

Magma could also be supplied to the upper mantle at the ends of the slow-spreading segments by lateral dike propagation from the segment center (Model 2 in Figure 5). Dike propagation over distances $>50 \mathrm{~km}$ has been documented at Krafla volcano in Iceland [Einarsson and Brandsdottir, 1980] and Axial volcano on the Juan de Fuca Ridge [Dziak and Fox, 1999; Embley et al., 2000]. Dikes tend to propagate laterally at the level of effective neutral bouyancy [e.g., Ryan, 1987]. In magma-starved regions this level is controlled by a combination of the rock and magma density, local stress state and magma pressure, and broadly corresponds to the depth of the brittle-ductile transition [Rubin, 1990]. Thus, if the brittleductile transition lies below the Moho at the segment end, dike propagation from the segment center could transport significant amounts of heat and magma to the upper mantle near segment ends [Fialko and Rubin, 1998].

Earthquake swarms are often associated with diking events and volcanic eruptions at mid-ocean ridges [e.g., Embley et $a l ., 1995]$. Since the installation of a NOAA/PMEL hydroacoustic network in the North Atlantic in 1999 [Smith et al., 2002] no earthquake swarms have been observed at any of the segments shown in Figure 2. However, at a spreading half-rate of $1-1.2 \mathrm{~cm} / \mathrm{yr}$ a $1-\mathrm{m}$ dike would be predicted only once every $40-50$ years. Thus, the lack of an observed event over the last 3 years does not preclude the lateral propagation of dikes as a viable mechanism for supplying heat to the ends of slow-spreading segments.

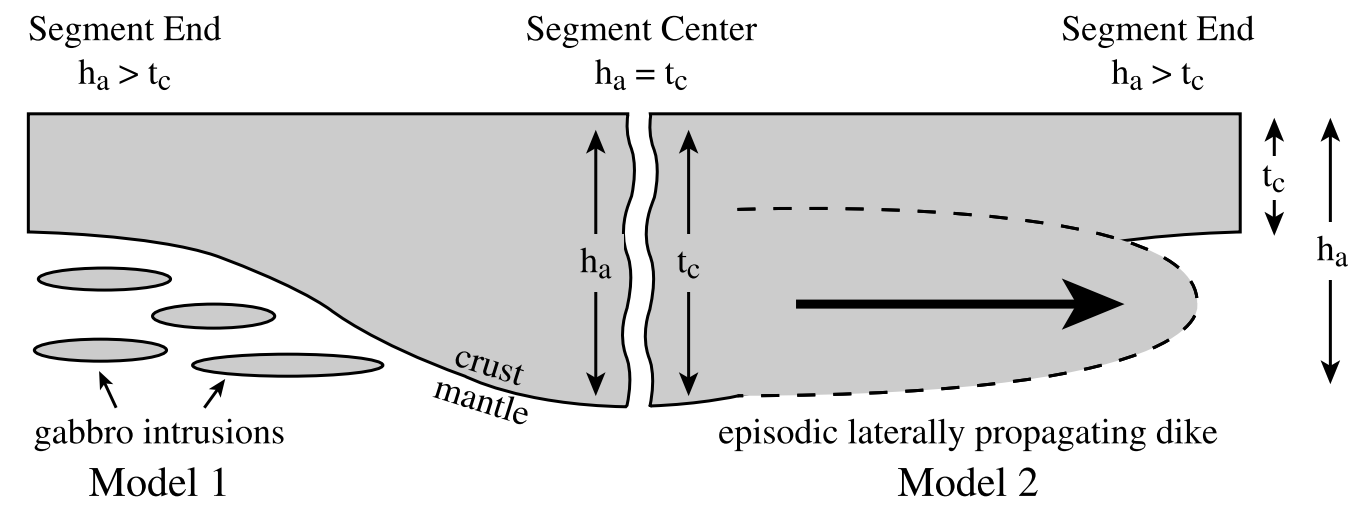

Figure 5. Schematic diagram of two possible mechanisms for magma injection in the upper mantle near the ends of the slow-spreading segments. (Left) Model 1: Rising asthenospheric melts crystallize below the Moho when temperatures in upper lithospheric mantle are below the melt solidus [e.g., Cannat, 1996]. (Right) Model 2: Magma is supplied to the segment ends via lateral dike propagation from the segment center [e.g., Fialko and Rubin, 1998]. Either of these mechanisms can result in an episodic magma injection zone at the segment end that is thicker than the seismically determined crustal thickness (i.e., $h_{a}>t_{c}$ ). 
The results of this study do not imply that sub-crustal heat input is required at the ends of all slow-spreading ridge segments. There is considerable evidence that slow-spreading ridges experience temporal variations in magma supply on time scales of 1-5 Myrs [e.g., Canales et al., 2000; Bonatti et al., 2003], which could strongly affect crustal and upper mantle thermal structure. In addition, transient magmatic events on shorter time scales may result in axial temperatures that are not in steady-state. However, the results presented here do illustrate the possible importance of sub-crustal accretion and the complexity in determining axial thermal structure in slowspreading environments.

\section{CONCLUSIONS}

We have shown the sensitivity of fault development in slowspreading environments to the efficiency of hydrothermal cooling and the magma injection zone near the ridge axis. The width of active deformation is calculated to increase with increasing efficiency of hydrothermal cooling and decreasing depth extent of the magma injection zone. We find that for a given set of thermal parameters, rift width is greater at the segment end than at the segment center, consistent with the results of earlier modeling studies [e.g., Shaw and Lin, 1993; 1996]. However, unlike these earlier studies, which assumed slip occurred on only one fault, our results predict that under certain circumstances multiple sets of inward-dipping faults may be active simultaneously.

Comparing our numerical results with the observed style of faulting at the center and ends of several segments along the MAR, we find that temperatures in the crust and upper mantle do not vary significantly along-axis. Specifically, the thermal regime at segment ends must be warmer than predicted by previous models in order to generate tectonic rift widths similar to those observed along the MAR. To produce these warm temperatures, we show that either hydrothermal cooling must be very inefficient in the shallow crust or that heat must be emplaced in the upper mantle due to magmatic accretion below the Moho. Geophysical and geochemical evidence supports efficient hydrothermal circulation in the shallow crust. Therefore, we favor a model in which heat is supplied to the upper mantle at the segment end by either crystallization of rising asthenospheric melts or episodic lateral dike propagation from the segment center.

Acknowledgments. This study benefited from constructive conversations with Roger Buck, Mathilde Cannat, Laurent Montési and Brian Tucholke. We thank Roger Searle, Lindsay Parsons, and an anonymous reviewer for their constructive comments that significantly improved an earlier version of this manuscript. This work was supported by a Carnegie Institution of Washington postdoctoral fel- lowship (M.B.); NSF grant EAR-0003888 and Andrew W. Mellon Foundation Endowed Fund for Innovative Research at WHOI (J.L.); and NASA Grant NAG5-4555 and a fellowship from the Radcliffe Institute for Advanced Study at Harvard University (M.Z.). WHOI contribution number 11090 .

\section{REFERENCES}

Barclay, A. H., D. R. Toomey, and S. C. Solomon, Microearthquake characteristics and crustal $\mathrm{Vp} / \mathrm{Vs}$ structure at the Mid-Atlantic Ridge, 35N, J. Geophys. Res., 106, 2017-2034, 2001.

Behn, M. D., J. Lin, and M. T. Zuber, A continuum mechanics model for normal faulting using a strain-rate softening rheology: Implications for thermal and rheological controls on continental and oceanic rifting, Earth Planet. Sci. Lett., 202, 725-740, 2002.

Bonatti, E., M. Ligi, D. Brunelli, A. Cipriani, P. Fabretti, V. Ferrante, L. Gasperini, and L. Ottolini, Mantle thermal pulses below the Mid-Atlantic Ridge and temporal variations in the formation of oceanic lithosphere, Nature, 423, 499-505, 2003.

Boutilier, R. R., and C. E. Keen, Geodynamic models of fault-controlled extension, Tectonics, 13, 439-454, 1994.

Buck, W. R., Effect of lithospheric thickness on the formation of high- and low-angle normal faults, Geology, 21, 933-936, 1993.

Byerlee, J., Friction of rocks, Pure Appl. Geophys., 116, 615-626, 1978.

Canales, J. P., J. A. Collings, J. Escartín, and R. S. Detrick, Seismic structure across the rift valley of the Mid-Atlantic Ridge at $23^{\circ} 20^{\prime} \mathrm{N}$ (MARK Area): Implications for crustal accretion processes at slowspreading ridges, J. Geophys. Res., 105, 28, 411-28, 425, 2000.

Cannat, M., F. Chatin, H. Whitechurch, and G. Ceuleneer, Gabbroic rocks trapped in the upper mantle at the Mid-Atlantic Ridge, in Proc. Ocean Drill. Program, Sci. Res., edited by Karson, J. A., M. Cannat, D. J. Miller, and D. Elthon, 153, pp. 243-264, College Station, TX, 1997.

Cannat, M., How thick is the magmatic crust at slow spreading oceanic ridges?, J. Geophys. Res., 101, 2847-2857, 1996.

Chen, Y. J., and J. Lin, Mechanisms for the formation of ridge-axis topography at slow-spreading ridges: A lithospheric plate flexure model, Geophys. J. Int., 136, 8-18, 1999.

Chen, Y. and W. J. Morgan, Rift valley/No rift valley transition at mid-ocean ridges, J. Geophys. Res., 95, 17,571-17,581, 1990a.

Chen, Y. and W. J. Morgan, A nonlinear rheology model for midocean ridge axis topography, J. Geophys. Res., 95, 17,583-17,604, $1990 \mathrm{~b}$

Chopra, P. N., and M. S. Paterson, The role of water in the deformation of dunite, J. Geophys. Res., 89, 7861-7876, 1984.

Cloos, E., Experimental analysis of gulf coast fracture patterns, $\mathrm{Am}$. Assoc. Petr. Geol. Bull., 52, 420-444, 1968.

Cowie, P. A., Normal fault growth in three-dimensions in continental and oceanic crust, in Faulting and Magmatism at Mid-Ocean Ridges, edited by Buck, W. R. and P. T. Delaney, and J. A. Karson, and Y. Lagabrielle, AGU Geophys. Monograph, 106, 325-348, 1998.

Davy, P., A. Hansen, E. Bonnet, and S.-Z. Zhang, Localisation and fault growth in layered brittle-ductile systems: implications for deformation of the continental lithosphere, J. Geophys. Res., 100, 6281-6289, 1995. 
Detrick, R. S., H. D. Needham, and V. Renard, Gravity anomalies and crustal thickness variations along the Mid-Atlantic Ridge between $33^{\circ} \mathrm{N}$ and $40^{\circ} \mathrm{N}$, J. Geophys. Res., 100, 3767-3787, 1995.

Dieterich, J. H., Modeling of rock friction 1. Experimental results and constitutive equations, J. Geophys. Res., 84, 2161-2168, 1979.

Dunn, R. A., D. R. Toomey, and S. C. Solomon, Three-dimensional seismic structure and physical properties of the crust and shallow mantle beneath the East Pacific Rise at $9^{\circ} 30^{\prime} \mathrm{N}, J$. Geophys. Res., $105,23,537-23,555,2000$.

Dziak, R. P. and C. G. Fox, The January 1998 earthquake swarm at Axial volcano, Juan de Fuca Ridge: Hydroacoustic evidence of seafloor volcanic activity, Geophys. Res. Lett., 26, 3429-3432, 1999.

Einarsson, P. and B. Brandsdottir, Seismological evidence for lateral magma intrusion during the July 1978 deflation of the Krafla volcano in NE-Iceland, J. Geophys., 47, 160-165, 1980.

Elthon, D., M. Stewart, and D. K. Ross, Compositional trends of minerals in oceanic cumulates, J. Geophys. Res., 97, 15189-15199, 1992.

Embley, R. W., W. W. Chadwick, I. R. Jonasson, D. A. Butterfield, and E. T. Baker, Initial results of the rapid response to the 1993 CoAxial event: Relationships between hydrothermal and volcanic processes, Geophys. Res. Lett., 22, 143-146, 1995.

Embley, R. W., W. W. Chadwick, M. R. Perfit, M. C. Smith, and J. R. Delaney, Recent eruptions on the CoAxial segment of the Juan de Fuca Ridge: Implications for mid-ocean ridge accretion processes, J. Geophys. Res., 105, 16,501-16,525, 2000.

Escartín, J., P. A. Cowie, R. C. Searle, S. Allerton, N. C. Mitchell, C.J. Macleod, and A. P. Slootweg, Quantifying tectonic strain and magmatic accretion at a slow spreading ridge segment, Mid-Atlantic Ridge, 29º N, J. Geophys. Res., 104, 10,421-10,437, 1999.

Escartín, J., G. Hirth, and B. Evans, Effects of serpentinization on the lithospheric strength and the style of normal faulting at slowspreading ridges, Earth Planet. Sci. Lett., 151, 181-189, 1997.

Fialko, Y. A. and A. M. Rubin, Thermodynamics of lateral dike propagation: Implications for crustal accretion at slow spreading midocean ridges, J. Geophys. Res., 103, 2501-2514, 1998.

Flower, M. F. J., Thermal and kinematic control on ocean-ridge magma fractionation: Contrasts between Atlantic and Pacific spreading axes, J. Geol. Soc. London, 138, 695-712, 1981.

Forsyth, D. W., Finite extension and low-angle normal faulting, Geology, 20, 27-30, 1992.

Forsyth, D. W. and B. Wilson, Three-dimensional temperature structure of a ridge-transform-ridge system, Earth Planet. Sci. Lett., 70, 355-362, 1984.

Gràcia, E., D. Bideau, R. Hekinian, and Y. Lagabrielle, Detailed geological mapping of two contrasting second-order segments of the Mid-Atlantic Ridge between Oceanographer and Hayes fracture

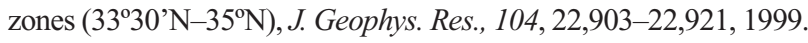

Heimpel, M. and P. Olsen, A seismodynamical model of lithospheric deformation: Development of continental and oceanic rift networks, J. Geophys. Res., 101 , 16,155-16,176, 1996.

Hirth, G., J. Escartin, and J. Lin, The rheology of the lower oceanic crust: Implications for lithospheric deformation at mid-ocean ridges, in Faulting and Magmatism at Mid-Ocean Ridges, edited by Buck, W. R. and P. T. Delaney, and J. A. Karson, and Y. Lagabrielle, AGU Geophys. Monograph, 106, 291-303, 1998.

Hooft, E. E. E., R. S. Detrick, D. R. Toomey, J. A. Collins, and J. Lin, Crustal thickness and structure along three contrasting spreading segments of the Mid-Atlantic Ridge, $33.5^{\circ} \mathrm{N}-35^{\circ} \mathrm{N}, J$. Geophys. Res., 105, 8205-8226, 2000.

Hosford, A., J. Lin, and R. S. Detrick, Crustal evolution over the last 2 m.y. at the Mid-Atlantic Ridge $\mathrm{OH}-1$ segment, $35^{\circ} \mathrm{N}, J$. Geophys. Res., 106, 13,269-13,285, 2001.

Kelley, D. S. and K. M. Gillis, Petrologic constraints upon hydrothermal circulation, in InterRidge Theoretical Institute: Thermal Regime of Ocean Ridges and Dynamics of Hydrothermal Circulation, edited by C. German, J. Lin, R. Tribuzio, A. Fisher, M. Cannat, and A. Adamczewska, InterRidge, Pavia, 2002.

Kirby, S, Rheology of the lithosphere, Rev. Geophys. Space Phys., 21, 1458-1487, 1983.

Kohlstedt, D., B. Evans, and S. Mackwell, Strength of the lithosphere: Constraints imposed by laboratory experiments, J. Geophys. Res., 100, 17587-17602, 1995.

Kuo, B. and D. W. Forsyth, Gravity anomalies of the ridge-transform system in the South Atlantic between $31^{\circ}$ and $34.5^{\circ} \mathrm{S}$ : Upwelling centers and variations in crustal thickness, Mar. Geophys. Res., 10, 205-232, 1988.

Lavier, L. L. and W. R. Buck, Half graben versus large-offset lowangle normal fault: Importance of keeping cool during normal faulting, J. Geophys. Res., 107, 10.1029/2001JB000513, 2002.

Lavier, L. L., W. R. Buck, and A. N. B. Poliakov, Factors controlling normal fault offset in an ideal brittle layer, J. Geophys. Res., 105, 23,431-23,442, 2000.

Lin, J. and E. M. Parmentier, A finite amplitude necking model of rifting in brittle lithosphere, J. Geophys. Res., 95, 4909-4923, 1990.

Lin, J. and E. M. Parmentier, Mechanisms of lithospheric extension at mid-ocean ridges, Geophys. J. Int., 96, 1-22, 1989.

Lin, J. and J. Phipps Morgan, The spreading rate dependence of three-dimensional mid-ocean ridge gravity structure, Geophys. Res. Lett., 19, 13-16, 1992.

Lin, J., G. M. Purdy, H. Schouten, J.-C. Sempéré, and C. Zervas, Evidence from gravity data for focused magmatic accretion along the Mid-Atlantic Ridge, Nature, 344, 627-632, 1990.

Lowell, R. P. and Y. Yao, Anhydrite precipitation and the extent of hydrothermal recharge zones at ocean ridge crests, J. Geophys. Res., 107, 2183, doi:10.1029/2001JB001289, 2002.

Macdonald, K. C., and P. J. Fox, The axial summit graben and crosssectional shape of the East Pacific Rise as indicators of axial magma chambers and recent volcanic eruptions, Earth Planet. Sci. Lett., 88, 119-131, 1988.

Macdonald, K. C. and B. P. Luyendyk, Deep-tow studies of the structure of the Mid-Atlantic Ridge crest near lat $37^{\circ} \mathrm{N}, G S A$ Bull., 88 , 621-636, 1977.

Mackwell, S. J., M. E. Zimmerman, and D. L. Kohlstedt, High-temperature deformation of dry diabase with application to tectonics on Venus, J. Geophys. Res., 103, 975-984, 1998.

Malinverno, A. and P. A. Cowie, Normal faulting and the topographic roughness of mid-ocean ridge flanks, J. Geophys. Res., 98, 17,921-17,939, 1993. 
Montési, L. G. J., and M. Zuber, A unified description of localization for application to large-scale tectonics, J. Geophys. Res., 107, 10.1029/2001JB000465, 2002.

Montési, L. G. J., and M. Zuber, Clues to the lithospheric structure of Mars from wrinkle ridge sets and localization instability, $J$. Geophys. Res., 108, 10.1029/2002JE001974, 2003.

Neumann, G. A., and M. T. Zuber, A continuum approach to the development of normal faults, in Proc. 35th US Symposium on Rock Mechanics, edited by J. Daemen and R. Schultz, pp. 191-198, Balkema, Lake Tahoe, Nevada, 1995.

Phipps Morgan, J. and Y. J. Chen, The genesis of oceanic crust: Magma injection, hydrothermal circulation, and crustal flow, $J$. Geophys. Res., 98, 6283-6297, 1993.

Phipps Morgan, J. and D. W. Forsyth, Three-dimensional flow and temperature perturbations due to a transform offset: Effects on oceanic crust and upper mantle structure, J. Geophys. Res., 93, 2955-2966, 1988.

Phipps Morgan, J., E. M. Parmentier, and J. Lin, Mechanisms for the origin of mid-ocean ridge axial topography: Implications for the thermal and mechanical structure of accreting plate boundaries, J. Geophys. Res., 92, 12,823-12,836, 1987.

Poliakov, A. N. B. and W. R. Buck, Mechanics of strectching elastic-plastic-viscous layers: Applications to slow-spreading mid-ocean ridges, in Faulting and Magmatism at Mid-Ocean Ridges, edited by Buck, W. R. and P. T. Delaney, and J. A. Karson, and Y. Lagabrielle, AGU Geophys. Monograph, 106, 305-323, 1998.

Rabain, A., M. Cannat, J. Escartín, G. Pouliquen, C. Deplus, and C. Rommevaux-Jestin, Focused volcanism and growth of a slowspreading segment (Mid-Atlantic Ridge, $35^{\circ} \mathrm{N}$ ), Earth Planet. Sci. Lett., 185, 211-224, 2001.

Ross, K. and D. Elthon, Cumulus and postcumulus crystallization in the oceanic crust: Major- and minor-element geochemistry of Leg 153 gabbroic rocks, in Proc. Ocean Drill. Program, Sci. Res., edited by Karson, J. A., M. Cannat, D. J. Miller, and D. Elthon, 153, pp. 333-350, College Station, TX, 1997.

Rubin, A. M., A comparison of rift zone tectonics in Iceland and Hawaii, Bull. Volcanol., 52, 302-319, 1990.

Ruina, A. L., Slip instability and state variable friction laws, J. Geophys. Res., 88, 10,359-10,370, 1983.

Ryan, M. P., Neutral buoyancy and the mechanical evolution of magmatic systems, in Magmatic Processes: Physiochemical Principles, edited by B. O. Mysen, pp. 259-288, Geochem Soc., University Park, Pa., 1987.
Scholz, C., The Mechanics of Earthquakes and Faulting, Cambridge University Press, New York, 1990.

Sempéré, J.-C., J. Lin, H. S. Brown, H. Schouten, and G. M. Purdy, Segmentation and morphotectonic variations along a slow-spreading center: The Mid-Atlantic ridge ( $\left.24^{\circ} 00^{\prime} \mathrm{N}-30^{\circ} 40^{\prime} \mathrm{N}\right)$, Mar. Geophys. Res., 15, 153-200, 1993.

Shaw, P. R., Ridge segmentation, faulting and crustal thickness in the Atlantic Ocean, Nature, 358, 490-493, 1992.

Shaw, P. R. and J. Lin, Causes and consequences of variations in faulting style at the Mid-Atlantic Ridge, J. Geophys. Res., 98, 21,839-21,851, 1993.

Shaw, W. J. and J. Lin, Models of ocean ridge lithospheric deformation: Dependence on crustal thickness, spreading rate, and segmentation, J. Geophys. Res., 101, 17,977-17,993, 1996.

Sinton, J. M. and R. S. Detrick, Mid-ocean ridge magma chambers, J. Geophys. Res., 97, 197-216, 1992.

Sleep, N. H., Hydrothermal circulation, anhydrite precipitation, and thermal structure at ridge axes, J. Geophys. Res., 96, 2375-2387, 1991.

Sleep, N. H. and B. R. Rosendahl, Topography and tectonics of midocean ridge axes, J. Geophys. Res., 84, 6831-6839, 1979.

Smith, D. K., M. Tolstoy, C. G. Fox, D. R. Bohnenstiehl, H. Matsumoto, M.J. Fowler, Hydroacoustic monitoring of seismicity at the slow-spreading Mid-Atlantic Ridge, Geophys. Res. Lett., 29, doi:10:1029/2001GL013912, 2002.

Stein, C. A., and S. Stein, A model for the global variation in oceanic depth and heat flow with lithospheric age, Nature, 359, 123-129, 1992.

Tolstoy, M., A.J. Harding, and J.A. Orcutt, Crustal thickness on the Mid-Atlantic Ridge: Bull's-eye gravity anomalies and focused accretion, Science, 262, 726-729, 1993.

Wolfe, C. J., G. M. Purdy, D. R. Toomey, and S. C. Solomon, Microearthquake characteristics and crustal velocity structure at $29^{\circ} \mathrm{N}$ on the Mid-Atlantic Ridge: The architecture of a slow spreading segment, J. Geophys. Res., 100, 24,449-24,472, 1995.

M. D. Behn, Department of Terrestial Magnetism, Carnegie Institution of Washington, 5241 Broad Branch Road NW, Washington, DC 20015. (behn@dtm.ciw.edu)

J. Lin, Department of Geology and Geophysics, Woods Hole Oceanographic Institution, Woods Hole, MA 02543. (jlin@whoi.edu)

M. T. Zuber, Department of Earth Atmospheric and Planetary Sciences, Massachusetts Institute of Technology, Cambridge, MA 02139. (zuber@mit.edu) 
